\title{
A Sensitive Fluorometric Assay of Glutathione Reductase Activity with $N$-(9-Acridinyl)maleimide
}

\author{
Tsuneo Kamata*, Kazuaki AKasaka**, Hiroshi OhruI** and Hiroshi Meguro** \\ *Division of Food and Nutrition, Jumonji Gakuen College, Sugasawa, Niiza 352, Japan \\ **Department of Applied Biochemistry, Faculty of Agriculture, Tohoku University, \\ Aoba, Sendai 981, Japan
}

Keywords $N$-(9-Acridinyl)maleimide fluorometry, glutathione reductase activity, spectrophotometry

Glutathione reductase (GR) (oxidized glutathione oxidoreductase, EC 1.6.4.2) catalyzes the reduction of oxidized glutathione (GSSG) to reduced glutathione (GSH) by NADPH (GSSG + NADPH $+\mathrm{H}^{+} \longrightarrow 2 \mathrm{GSH}$ $+\mathrm{NADP}^{+}$). The enzyme activity has been determined from the rate of formation of $\mathrm{GSH}^{1,2}$ or $\mathrm{NADP}^{3}$ or from the rate of decrease of GSSG or NADPH. ${ }^{4,5}$ The most popular method is to monitor the UV absorption of NADPH at $340 \mathrm{~nm}$. The method is selective but not sensitive, so it needs a large amount of enzyme preparation and is liable to lead to errors.

A highly sensitive method was reported to detect released GSH using $N$-(9-acridinyl)maleimide (NAM) fluorometry. ${ }^{6}$ In this study, we apply the NAM fluorometry to measure GR activities of the liver and plasma samples and compare this procedure with the conventional spectrophotometries.

\section{Materials and Methods}

\section{Reagents and enzyme sources}

Most of the analytical grade reagents were purchased from Sigma Chem. Co., diluted and kept in an ice bath before use. Purified GR from Oriental Yeast Co. was diluted with $50 \%$ glycerin and stored in a freezer. Human plasmas from three individuals were frozen for 1 year. Liver homogenates were prepared from bovine, pig, sheep and chicken directly after slaughter. The livers were sliced, rinsed in $0.25 \mathrm{M}$ sucrose at $5^{\circ} \mathrm{C}$, and homogenized in 3 volumes of $0.25 \mathrm{M}$ sucrose on ice for $2 \mathrm{~min}$ at $15000 \mathrm{rpm}$. These were filtered by gauze and centrifuged at $2000 \times g$ for $10 \mathrm{~min}$. The soluble fractions were obtained by centrifugation at $105000 \times g$ for $60 \mathrm{~min}$ and stored at $-20^{\circ} \mathrm{C}$ under nitrogen atomosphare. The protein content $(\mathrm{mg} / \mathrm{ml})$ of liver homogenates and human plasmas were determined by dyebinding assay ${ }^{7}$ with bovine $\gamma$-globulin as a standard.
Determination of $G R$ activity by the conventional spectrophotometry ${ }^{8}$

Standard GR was prepared by dilution of the stock solution in the range of 80 to 400 milli units $/ \mathrm{ml}$ with the $0.1 \mathrm{M}$ potassium phosphate buffer at $\mathrm{pH} 7.5$ containing $0.5 \%$ bovine serum albumin. Liver homogenates were diluted twice with the same buffer. GR activity was measured at $25^{\circ} \mathrm{C}$ by monitoring the decrease in absorbance at $340 \mathrm{~nm}$ in the solution containing $0.7 \mathrm{ml}$ of $0.1 \mathrm{M}$ sodium phosphate at $\mathrm{pH} 7.5,0.1 \mathrm{ml}$ of $10 \mathrm{mM}$ GSSG, $0.1 \mathrm{ml}$ of $3 \mathrm{mM}$ NADPH and $0.1 \mathrm{ml}$ of GR. The oxidation of $1 \mu \mathrm{mol} / \mathrm{min}$ NADPH is used as a unit of GR activity under these conditions. The specific activity is expressed as units/mg protein.

\section{Determination of GR activity by NAM fluorometry}

NADPH and GSSG were dissolved in $0.1 \mathrm{M}$ sodium phosphate at pH 7.5. Purified GR was diluted 1.0 to 20 milli units/ml, liver homogenates 50 to 200 times and human plasmas 10 times with $10 \mathrm{mM}$ Tris. A reaction mixture, containing $0.1 \mathrm{ml}$ of $2 \mathrm{mM}$ GSSG and $0.1 \mathrm{ml}$ of enzyme sample, was preincubated at $25^{\circ} \mathrm{C}$ for $10 \mathrm{~min}$. The reaction was started by adding $0.1 \mathrm{ml}$ of $0.5 \mathrm{mM}$ NADPH, and was stopped after $5 \mathrm{~min}$ by the addition of $0.1 \mathrm{ml}$ of $0.5 \mathrm{M} \mathrm{HCl}$. To the reaction mixture (total volume of $0.4 \mathrm{ml}$ ) was added $3.0 \mathrm{ml}$ of the $0.5 \mathrm{M}$ boron carbonate buffer at $\mathrm{pH} 8.8$, and $0.1 \mathrm{ml}$ of $0.25 \mathrm{mM}$ NAM acetone solution. The fluorescence intensity (FI) was measured at $435 \mathrm{~nm}$ (excitation at $360 \mathrm{~nm}$ ) by Hitachi 204 fluorescence spectrophotometer after the mixture was kept at room temperature for $45 \mathrm{~min}$ in the dark. Background of FI at zero time was assayed simultaneously. A unit of specific GR activity was expressed as $1 \mu \mathrm{mol}$ GSSH reduced $/ \mathrm{min} / \mathrm{mg}$ protein.

\section{Results and Discussion}

Optimum conditions for enzyme assay

Hydrochloric acid destroys NADPH. ${ }^{9}$ We used 
$0.1 \mathrm{ml}$ of $0.5 \mathrm{M} \mathrm{HCl}$ to eliminate the fluorescence of NADPH below $0.1 \mu \mathrm{mol}$ without any influences on the NAM fluorometry and to stop the enzyme reaction.

The effects of the substrate concentrations were examined in $0.1 \mathrm{M}$ sodium phosphate, $0.1 \mathrm{M}$ Tris-malate and $0.1 \mathrm{M}$ triethanolamine hydrochloride at $\mathrm{pH} 7.5$ with purified GR. Figure 1 shows the optimum concentrations of the substrates, $0.17 \mathrm{mM} \mathrm{NADPH}$ and $0.67 \mathrm{mM}$ GSSG, in these buffers and the maximum $\Delta \mathrm{FI}$ (FIbackground FI) in $0.1 \mathrm{M}$ sodium phosphate. Figure 2 shows the relationships between $\Delta F I$ and the $\mathrm{pH}$ of the $0.1 \mathrm{M}$ sodium phosphate buffer from $\mathrm{pH} 6.5$ to 8.5 using 0.1 to 2.0 milli units of purified $\mathrm{GR}$ at $25^{\circ} \mathrm{C}$ for $5 \mathrm{~min}$. The maximum $\Delta \mathrm{FI}$ was observed at $\mathrm{pH}$ 7.5.

We also studied the effects of incubation temperatures from 20 to $35^{\circ} \mathrm{C}$ and of enzyme concentrations. Figure
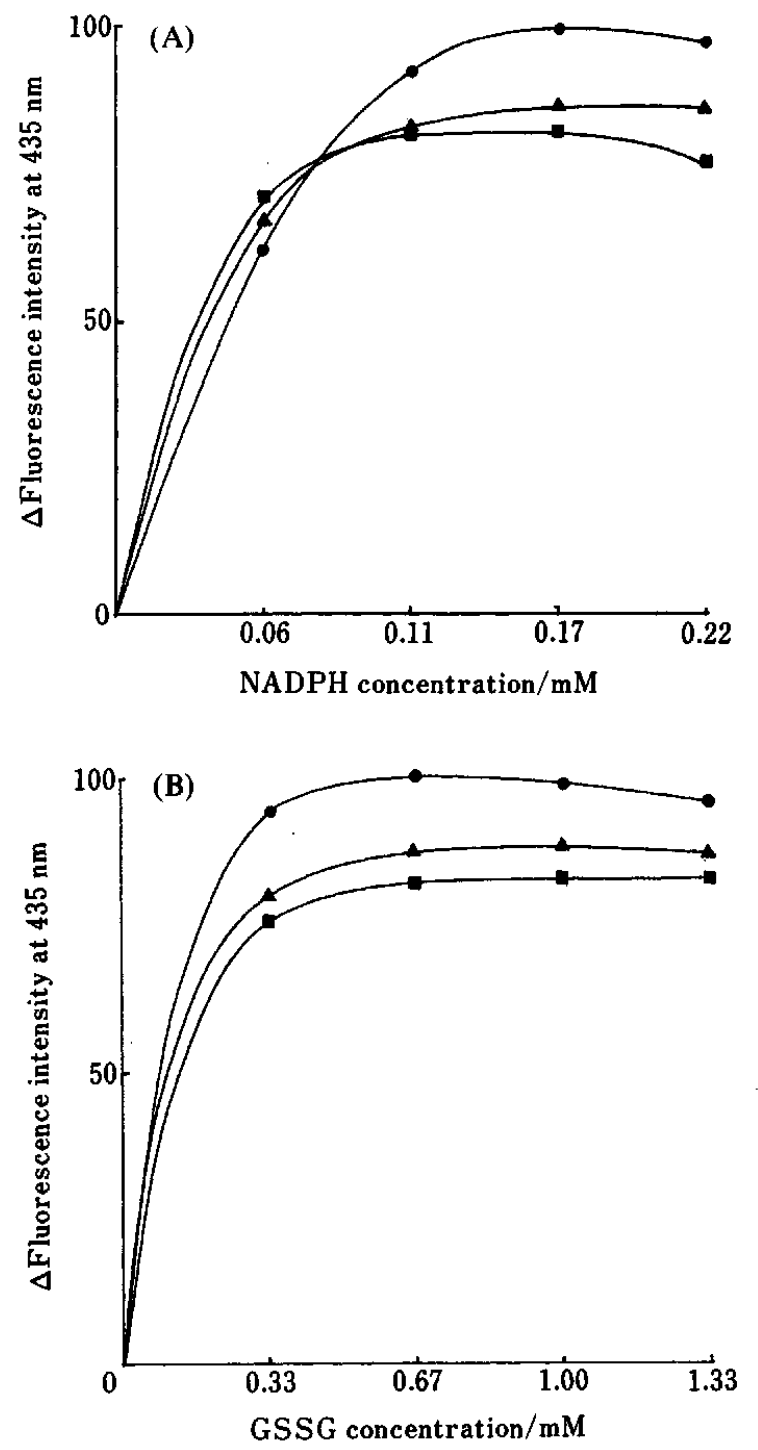

Fig. 1 The optimum concentrations of the substrate in three different buffers at $\mathrm{pH} 7.5(\boldsymbol{O}, 0.1 \mathrm{M}$ sodium phosphate; $\boldsymbol{\Delta}$, $0.1 \mathrm{M}$ triethanolamine $\mathrm{HCl} ; \mathbf{\square}, 0.1 \mathrm{M}$ Tris malate) with 1.0 milli unit purified glutathione reductase at $25^{\circ} \mathrm{C}$ for 5 min: (A), NADPH (using $0.67 \mathrm{mM} \mathrm{GSSG}$ ); (B), GSSG (using $0.17 \mathrm{mM} \mathrm{NADPH}$ ).
3 shows the linear increase of $\Delta \mathrm{FI}$ against the temperature and GR concentrations. The enzyme assay was thus carried at $25^{\circ} \mathrm{C}$.

FI was recorded at 2 min intervals using diluted bovine liver homogenate and human plasma under the optimal conditions (Fig. 4). FI increased linearly against the incubation time within at least $6 \mathrm{~min}$. We selected the

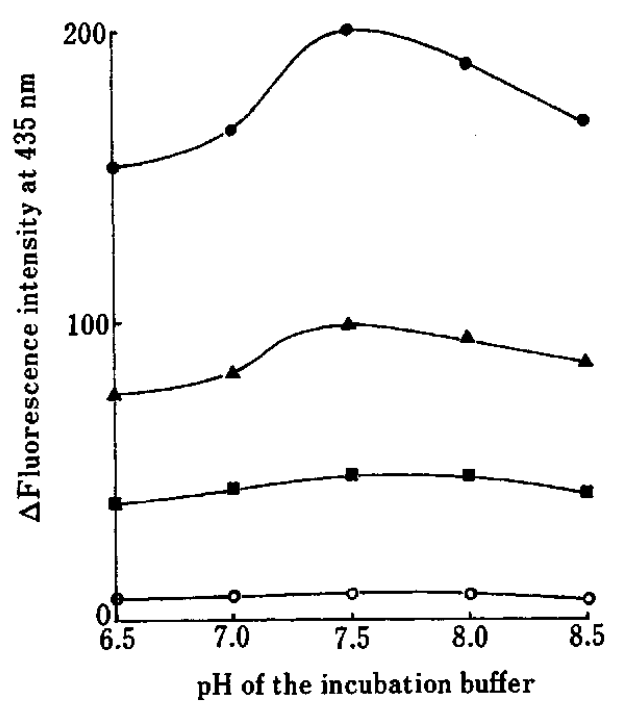

Fig. 2 Relationship of $\Delta$ fluorescence intensity and $\mathrm{pH}$ of the incubation medium ( $0.1 \mathrm{M}$ phosphate buffer at $\mathrm{pH} 6.5$ to 8.5 ) with 0.1 to 2.0 milli unit purified glutathione reductase at $25^{\circ} \mathrm{C}$ for 5 min. 2.0 milli units; $\Delta, 1.0$ milli unit; 0.5 milli units; $O, 0.1$ milli units.

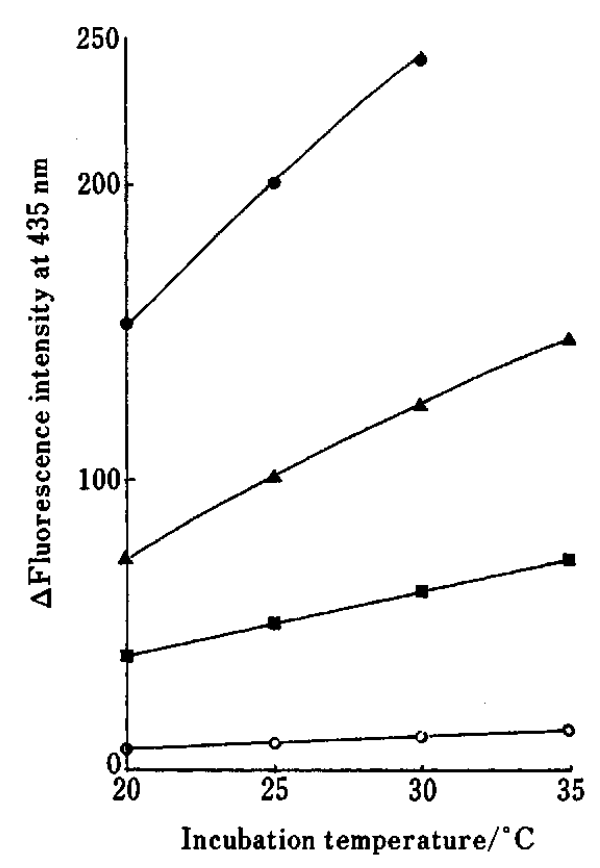

Fig. 3 Relationship of $\Delta$ fluorescence intensity and incubation temperature at 20 to $35^{\circ} \mathrm{C}$ for $5 \mathrm{~min}$ in $0.1 \mathrm{M}$ phosphate buffer at $\mathrm{pH} 7.5$, with 0.1 to 2.0 milli units of purified glutathione reductase. $\quad 2.0$ milli units; $\Delta, 1.0$ milli unit; 口, 0.5 milli units; $\bigcirc, 0.1$ milli units. 
Table 1 Specific glutathione reductase activities in purified glutathione reductase, liver homogenates of four types of animals and human plasma by NAM fluorometry and spectrophotometry

\begin{tabular}{|c|c|c|c|c|c|}
\hline \multirow{2}{*}{ Sample } & \multirow{2}{*}{ Protein content $/ \mathrm{mg} \mathrm{ml}^{-1}$} & \multicolumn{2}{|c|}{ NAM fluorometry } & \multicolumn{2}{|c|}{ Spectrophotometry } \\
\hline & & Activity $^{\mathrm{a}}$ & Sample size & Activity $^{\mathrm{a}}$ & Sample size $\mathrm{e}^{\mathrm{b}}$ \\
\hline $\mathrm{GR}^{\mathrm{c}}$ & & $224 \pm 5$ & $(4.5)$ & $184 \pm 12$ & $(118)$ \\
\hline Liver: Bovine & 14.8 & $70 \pm 2$ & $(15)$ & $52 \pm 4$ & $(740)$ \\
\hline : Pig & 18.2 & $54 \pm 1$ & $(18)$ & $37 \pm 2$ & (910) \\
\hline : Sheep & 18.7 & $7.3 \pm 0.2$ & (187) & $3.1 \pm 0.6$ & $(1870)$ \\
\hline : Chicken & 14.9 & $17.9 \pm 0.4$ & $(50)$ & $12.3 \pm 2.0$ & ( 745$)$ \\
\hline Plasmad: A & 37.9 & $0.35 \pm 0.02$ & $(380)$ & $0.13 \pm 0.06$ & $(1140)$ \\
\hline$: \mathbf{B}$ & 40.9 & $0.40 \pm 0.02$ & $(410)$ & $0.19 \pm 0.06$ & (1230) \\
\hline$: \mathrm{C}$ & 57.5 & $0.32 \pm 0.02$ & (575) & $0.04 \pm 0.04$ & (1150) \\
\hline
\end{tabular}

a. Specific glutathione reductase activity (purified glutathione reductase: units/mg protein; liver homogenates and human plasmas: milli units/mg protein) are shown as mean \pm SD for 8 samples. b. Sample size means protein weight of the samples (purified glutathione reductase: ng; liver homogenates and human plasmas: $\mu$ g). c. Purified glutathione reductase (indicated specific activity: 169 units/mg protein). d. Human plasma from three individuals for blood transfusion.

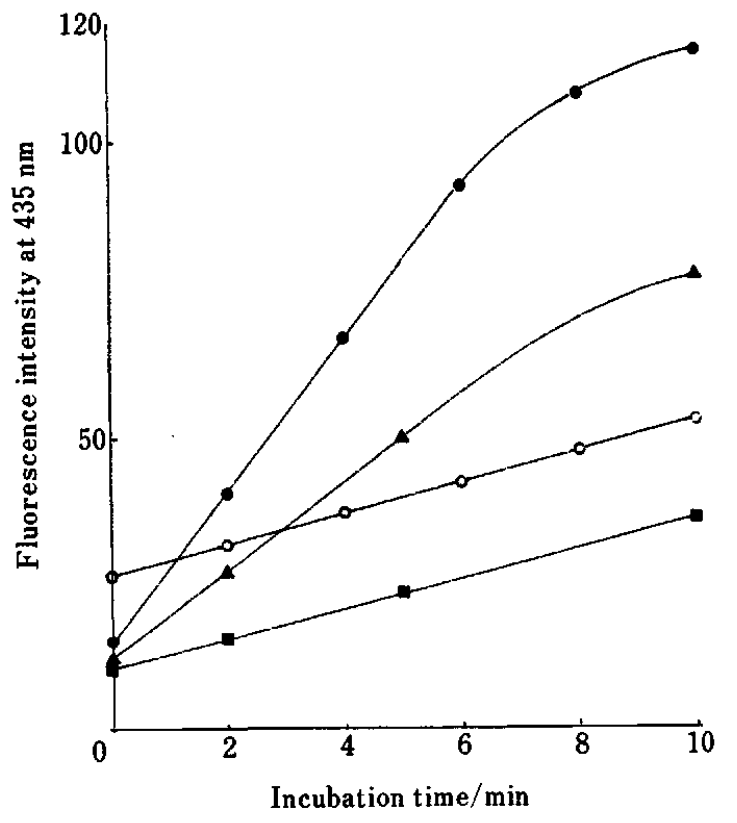

Fig. 4 Linear increase of fluorescence intensity in time course of incubation with diluted bovin liver homogenates $(\boldsymbol{C}$, 100 fold; $\Delta, 200$ fold; $\square, 500$ fold) and diluted human plasma $A(O, 10$ fold $)$ under the optimal conditions.

incubation time of $5 \mathrm{~min}$ and background FI of zero time as blank. The increase of FI was proportional to the concentrations of bovine liver homogenate in the range of 100 to 500 fold dilutions. Ten times dilution was suitable to meet the low activities in human plasma samples.

It has been proposed to add FAD in the determinations of GR activities, since GR is activated by binding of FAD to apoenzyme. No effect was observed in our experiments when 0.1 to $1.0 \mathrm{nmol} F A D$ was added to the liver homogenates and human plasma.
Determination of specific $G R$ activities in liver homogenates and human plasmas by NAM fluorometry and spectrophotometry

The specific activities of the enzyme were determined in the purified GR solutions, liver homogenates and human plasmas by NAM fluorometry and spectrophotometry. Table 1 shows the values with the sample sizes and the standard deviations. In liver homogenates, the values of the new method $(y)$ were 1.2 to 2.7 times higher than those of the spectrophotometry $(x)$. A linear relation was observed between them $(y=1.2 x+3.6)$. The precisions of NAM fluorometry were 2 to 8 times higher than those of the conventional spectrophotometry. It was necessary to use large amounts of samples to measure such low activities as those of human plasma by this spectrophotometry. Hence, with human plasma, the measurements and the precision by NAM fluorometry were 2 to 8 and 6 to 20 times, respectively, better than those by the spectrophotometry.

The sensitivity of NAM fluorometry was 10 to 50 times higher than that of the spectrophotometry. The higher dilution also reduced impurities in the incubation mixtures which greatly improved the accuracy. The NAM fluorometry was convenient to deal with samples with relatively low activity. It is also convenient to determine many samples at one time and wide range of sample sizes.

\section{References}

1. I. K. Smith, T. L. Vierheller and C. A. Thorme, Anal. Biochem., 175, 408 (1988).

2. S. S. M. Hassan and G. A. Rechnitz, Anal. Chem., 54, 1972 (1982).

3. C. Weiss, H. S. Maker and G. M. Lehrer, Anal. Biochem., 106, $512(1980)$.

4. F. Tietze, Anal. Biochem., 27, 507 (1967).

5. C. Calberg and B. Mannervik, "Method in Enzymology", Vol. 113, p. 484, Academic Press Inc., New York, 1985. 
6. Y. Nara and K. Tuzimura, Agric. Biol. Chem., 42, 793 (1978).

7. M. Bradford, Anal. Biochem., 72, 248 (1976).

8. Oriental Yeast Co., Technical Reports, “Assay procedure of GR from yeast".

9. O. H. Lowry and J. V. Passonnen, "A Flexible System of
Enzymatic Analysis", p. 13, Academic Press Inc., New York, 1972.

(Received July 27, 1993)

(Accepted September 21, 1993) 